\title{
Attachment Styles and Self-Esteem among Adolescents
}

\author{
* Sanober Jamil \\ ** Dr. Hina Ayaz Habib (Corresponding Author) \\ ** Laila Lodhia
}

\begin{abstract}
The current research aims to find the relationship between secure attachment style and self-esteem among latency adolescence. The assumptions developed for the study stated that a) secure attachment style would be positively correlated with self-esteem among Adolescents. b) Insecure attachment style (anxious and avoidant) would be negatively correlated with self-esteem among adolescents. The sample of the study comprised of 180 adolescents including 90 male and 90 female adolescents with age ranges between 12 to 16 years $(M=13.27, S D=1.13)$ were selected through purposive sampling technique from private schools based in Karachi, Pakistan. After taking approval from the authorities, the participant's assent to participate in the research was taken and a demographic form was administered. To measure the effect of attachment on self-esteem, the Attachment Style Classification Questionnaire (Finzi et al., 1996) and the Rosenberg Self Esteem Scale (Rosenberg, 1965) were used. Descriptive statistics and Pearson product-moment coefficient of correlation were applied to study the correlation among the study variables. The finding shows a noteworthy relationship between secure attachment styles and self-esteem was found with an r-value of .118 and a P value of .116.
\end{abstract}

Keywords: Adolescent, Attachment Styles, Secure Attachment, self-esteem, Depression. Introduction

Extensive research and literature in developmental and child and adolescent psychology have focused on understanding the effects of developmental trauma - how life stress in the early years affects psychological and emotional development in children and how this goes on to affect adult behavior patterns. Notably important is Bowlby's (1969) work on attachment, later expanded upon by Ainsworth (1973).

\section{Attachment Theories}

Bowlby proposed in his attachment theory (1988) that based on the interaction that children experience with primary caregivers, mental representations are formed about caregivers, which help the child to navigate through adult relationships later in life. This navigation can be either adaptive or maladaptive, based on factors such as home environment and rearing styles of parents (Hinnen, Sanderman, \& Sprangers, 2009). Attachment theory places great importance on the relationship that develops between the ages of 6 months to 2 years between child and caregiver, during which the child aims to develop a close bond and functional relationship in their early years. How this relationship develops (i.e. based on how the caregiver responds to the child's needs and demands) determines whether the child will go on to have relatively normal development in terms of social and emotional functioning (Bowlby, 1969; Ainsworth, 1973). Attachment theory emphasizes the bond between the infant and a primary caregiver, in which the infant's energy is mainly focused on seeking proximity most notably with the mother, particularly in stressful situations.

Infants seek out adults who are responsive and sensitive to the child's needs in social interactions and maintain consistency in these interactions. This consistency helps the child to identify a "secure base" (Ainsworth, 1973) - a parental figure to whom they can attach themselves to and feel secure enough to explore away from and return to. How the parent responds to the child's exploration and returning leads to the development of attachment patterns. These attachment patterns become a

\footnotetext{
* Institute of Clinical Psychology, University of Karachi Email: sanober.psy@gmail.com

** Institute of Clinical Psychology, University of Karachi Email: drhinaayazhabib@uok.edu.pk

*** Cedar School, Karachi Email: laila.lodhia@gmail.com
} 
part of the child's personality in terms of internal working models that help guide his or her cognitions, emotions, and expectations in adult relationships. (Bretherton \& Munholland, 1999; (Schimmenti et al, 2013; Schimmenti et al, 2014).

Internal working models, which are primarily based on the beliefs that one holds about themselves and those around them (Bartholomew \& Horowitz, 1991), tend to remain constant over time (Fraley, 2002). The internal working model develops based on the individual's attachment patterns and relates to the individual's state of mind in light of these attachment patterns. It explores the dynamics of functional relationships of individuals based on the individual's childhood experiences up to adolescence. Those who develop stable attachments are more likely to develop healthy internal working models as opposed to those who, as a result of insecure attachment styles, tend to rely more on their state of mind in the process of new attachment formation.

\section{Attachment Patterns and their Significance}

Ainsworth proposes four types of possible attachment patterns that can develop as a result of infantparent relationships, including avoidant or dismissing, anxious or preoccupied, secure or autonomous, and disorganized or unresolved. The three main attachment styles found in adults were classified by Hazan and Shaver (1989) as secure, avoidant, and ambivalent.

The course of the relationship and the experience of connection that infants feel throughout their lives can be predicted by the type of relationship they have with their primary caregivers. It has been found that adolescents with secure attachment styles hold their mothers in higher regard than any other supportive figures in their lives, including fathers, as well as friends and significant others. On the other hand, adolescents with insecure attachment styles hold their peers in higher regard than their primary caregivers, who fail to provide a sense of secure attachment. They view their friends as their primary source of attachment and support. Furthermore, adolescents with avoidant attachment styles consider no one but themselves as their primary support, holding both parents and peers in low regard. Finally, adolescents with anxious attachment styles, while viewing themselves as less significant, hold their parents in high regard for support (Freeman \& Brown, 2001)

Research has indicated that children who experience abuse in early childhood are prone to developing ambivalent attachment patterns (McCarthy \& Taylor, 1999). These children are inhibited in the exploration of their environments and in forming new relationships, often wary of strangers. Anxious-ambivalent children tend to experience high levels of distress in the absence of their caregivers, and high ambivalence towards the caregiver upon their return (Ainsworth et al, 1978). Not only can these children not depend on their caregivers, but they cannot also soothe and compose themselves in times of distress. In later life, these children are found to have trouble in maintaining healthy and stable intimate relationships in their adult lives (McCarthy \& Taylor, 1999), as they are hesitant in forming close bonds with others, often driven by a fear of rejection. Children with anxious attachment patterns are those who experience inconsistency in support from primary caregivers and find themselves experiencing rejection in the relationships. As a result, they undertake a life position of "You're okay, I'm not okay", i.e. internalizing a negative concept of self and a positive concept of others. (Levy et al., 1998). This experience of the negative concept of self in relationships takes the form of uncertainty and anxiety regarding acceptance. As a means of validation, they often seek out others' approval. (Bartholomew, 1990).

Children who develop avoidant attachment patterns tend to ignore (i.e. avoid) caregivers and often exhibit little to no emotional experience in both the presence and the absence of caregivers, while also being inhibited in the exploration of their surrounding environment and relationships. (Ainsworth \& Bell, 1970). As a result of developing an "I'm okay, you're not okay" stance, they rarely rely on others for support or validation. These children experienced harsh and rejecting parenting interactions (Levy et al., 1998), thus learning that interactions with others are painful. (Shaver \& Hazan, 1988). As a result, they adapt themselves to the world in a way that lacks trust (Feeney \& Noller, 1990), and thus, under the guise of independence, maintain emotional distance (Bowlby, 1982; Brennan \& Bosson, 1998; Mikulincer, 1998a; Shaver \& Hazan, 1988). They, therefore, can develop a positive mental model of the self and are adequately able to rely on themselves (Park et al., 2004).

Disorganized attachment patterns generally result when the child is driven by the experience of fear and is unable to coordinate himself in a fluent way to achieve a sense of proximity with the caregiver; there is a "disruption" or "flooding" in the attachment. They lack consistency in managing 
separation and reunion with caregivers and often appear to be clinically depressed. (Colin \& Low, 1991).

Individuals who successfully develop the most adaptive style of attachment, Secure attachment, believe others to be trustworthy and worthy of love. This results from a sense of having a secure base to return to after exploration, being met with love and affection by caregivers who are consistent in their child-rearing practices and are present when the child expects them to be, i.e. their needs are met inappropriately ways. The consistent sense of security and helpful assistance provided by the parent helps the child discover appropriate coping mechanisms and problem-solving abilities (Aronoff, 2012). Along with having higher self-esteem, these children also have a higher sense of self-reliance, being more independent, and suffer from fewer instances of emotional pathology. They are also better able to form stable and long-standing relationships. (Cherry, 2006). As they are better able to share their feelings with significant people in their lives, they are more successful in seeking out support and social connection, and experience trusting relationships. (Huber, 2014)

Overall, securely attached children regarding their early upbringing and familial relationships, report more positive instances and memories (Feeney \& Noller, 1990). As adolescents, they are better able to adjust to their environments as opposed to those who experience insecure attachments (Cooper, Shaver, \& Collins, 1998). Furthermore, being able to demonstrate assertiveness and confidence in social situations, they have a strong sense of internal security (Collins \& Read, 1990; Park et al., 2004).

Research has consistently indicated that all four domains of development (i.e. physical, psychological, social, and emotional) are correlated with secure and insecure attachment. Securely attached individuals are found to experience less stressful relationships and are better able to deal with stressors by being able to turn to social support networks during their adolescent years (SeiffgeKrenke, 2006). Having strong familial and social relationships is not only positively correlated with positive development in adulthood, but also with better adjustment in other areas of life, such as school, as well as better overall emotional control (O'Connor et al., 2011).

\section{Clinical Significance of Attachment Patterns}

In a study conducted by Lyons-Ruth it was found that "for each additional withdrawing behavior displayed by mothers concerning their infant's attachment cues in the Strange Situation Procedure, the likelihood of clinical referral by service providers was increased by $50 \%$." (Lyons-Ruth et al, 2013).

\section{Adjustment}

A widespread body of studies indicates a significant relationship between attachment patterns and functioning in youngsters across several domains (Pearce \& Pezzot-Pearce, 2007). Even though insecure attachment styles in early childhood do not always predict difficulties, it does account for difficulties in life, especially if the insecure attachment styles through parental rearing patterns remain consistent (Karen, 1998). Insecure children do not exhibit sound adjustment, especially in relationships, as do those who are securely attached. This often threatens their relationships in the future. Although there is still much room for research available in this domain, it has become clear that infants who experience secure attachments grow up to be more competent in social situations, intellectual development, and identity formation. Whether children are viewed as popular, rejected, or neglected, predicts adjustment later in life (Schaffer, 2007)

\section{Emotionality}

Research has consistently indicated a correlation between attachment styles and emotional profiles (Consedine \& Magai, 2003). In general, positive feelings are associated with styles of secure attachment, while negative feelings correlate more with insecure styles of attachment (Hazan \& Shaver, 1987; Schimmenti \& Bifulco, 2013). Insecure individuals are more prone to experiencing negative emotions like increased anger and depression than their secure counterparts. However, literature does suggest that insecure attachment does not merely result in depression, but rather establishes various vulnerabilities that ultimately result in depression, like difficulty in accumulating a healthy sense of social support, poor self-image, and fear of rejection and abandonment (Blatt, 1974; Pierce \& Sarason, 1990). For example, in a study by Lee and Hankin (2009), it was shown that dysfunctional attitudes coupled with feelings of low self-esteem were greatly linked to anxiety and depression in adolescents with anxious attachment patterns (Lee \& Hankin, 2009). 


\section{Shame}

Research has indicated a link between insecure attachment styles and feelings of shame (Pace \& Zappulla, 2011, 2013; Schimmenti, 2012). Psychological literature defines shame as an emotion that causes a person to feel self-conscious, along with feeling exposed, devalued, and ridiculed. Behaviorally, shame can be identified in an individual through escaping eye contact, hiding, escaping, lowering of the head and hunching of the shoulders, and blushing. As is true for all experiences of damaged self, pathological shame finds its roots in maladaptive attachment experiences, particularly when a child experiences rejection or unhealthy separation from primary caregivers (Schore, 1998).

\section{Attachment and Self-Esteem}

As children transition from childhood into adolescence, the need to establish an identity becomes a prime focus. During this time, the individual experiences navigating through the conflict of identity vs. identity confusion in which the child seeks out autonomy and independence, particularly from parents (Erikson, 1950; Santrock, 1997). Successful resolution of this conflict results in the development of a healthy sense of self with both one's self (in terms of thoughts and desires) as well as to others (in terms of relationships). According to Santrock (1997), "the global evaluative dimension of the self is self-esteem, defined as "a measure of an individual's overall evaluation of his or her self-worth" (Marsh \& O'Mara, 2008; Rosenberg, 1965). Traditionally, "self-esteem has been viewed as global, unidirectional and independent of sources of influence like individual and contextual factors, particularly the impact of relationships with significant others" (DuBois \& Hirsch, 2000).

While studies have shown that self-esteem is correlated with attachment patterns (i.e. whether individuals' distinctive feelings of self-worth are in elevation or little), little is identified about how the attachment system is linked to other essential components of self-esteem. In terms of attachment and self-esteem, studies have indicated that secure attachment to parents may defense emotional distress, assist social competence, and improve self-esteem (Santrock, 1997). Where one perceives themselves as being incompetent and often experience feelings of rejection, feelings of loneliness can manifest, consequently affecting self-esteem. (Demir \& Tarhan, 2001).

Many previous studies have analyzed the effects of attachment on self-esteem or self-worth in adolescence. In a study by Srouf (2005) conducted over 30 years which evaluated participants from birth to adulthood, it was found that individuals with a history of secure attachment were rated by teachers and counselors as having higher self-confidence, self-esteem, and ego-resilience. On the other hand, those with insecure attachment patterns scored lower on these domains. Furthermore, those with a history of secure attachment were also found to be more flexible, resilient, curious, and explorative, and were less likely to react poorly to negative life events and less prone to experience anxiety in unpredictable circumstances (Sroufe, 2005).

Research has further confirmed that secure individuals score higher on self-esteem measures than those with ambivalent attachment styles. (Bylsma, Cozzarelli, \& Sumer, 1997; Collins \& Read, 1990; Feeney \& Noller, 1990; Griffin \& Bartholomew, 1994; Mikulincer, 1995).

In a study conducted by Salzman (1996), it was found that college-aged female adolescents with secure attachments are more likely to not only have higher self-esteem but also higher overall wellbeing than those with insecure attachment styles. Furthermore, the study revealed that those with anxious and ambivalent attachment patterns reported higher instances of depression than those with secure attachment patterns, along with lower levels of self-esteem. It was also shown that those with ambivalent attachment styles as children, experienced strong negative identification with maternal figures; they exhibited behavior that spread across the spectrum, both feeling clingy and needy for love, yet distant due to fear of rejection. This of course leads to difficulties in forming healthy identities as they find it challenging to successfully overcome the feat of individuation. For those with avoidant attachment styles, it was found that their scores lie between the results of those with secure attachment and those with ambivalent attachments, on measures of self-esteem and depression (Salzman, 1996).

\section{Method}

\section{Participants}

The sample of the current study comprised of 180 children ( 90 boys and 90 girls) with age ranges from 12 to 16 years (mean 13.27, SD 1.13) (see Table 1 for demographic information) were selected through purposive sampling technique from different schools of Karachi, Pakistan. 


\section{Measures}

\section{Informed Assent Form:}

To seek volunteer participation and resolve queries of respondents, basic information about the study was provided. The confidentiality of the data was also ensured that it will only be used for research purposes.

\section{Demographic Datasheet:}

A demographic information sheet was presented to gather particulars of the respondents such as their age, gender, birth order, family structure, personal and socioeconomic status, and grade level.

\section{Attachment Style Classification Questionnaire (Finzi et al., 1996)}

The Attachment style questionnaire for children-ASQC (Finzi et al, 1996) is an adaptation of Hazen and Shaver's (1987) questionnaire for adults. The 15-item questionnaire divided into three subscales assesses the child's attachment patterns according to Ainsworth's original classifications of secure, anxious, and avoidant. The 5-point rating scale ranges from 1 (not at all) to 5 (very much). The internal consistency for the subscales of anxious style and avoidant style was $\alpha=.80$ and $\alpha=.70$ respectively.

\section{Rosenberg Self Esteem Scale (Rosenberg, 1965).}

The Rosenberg Self-Esteem Scale is a 10-item self-report measure measuring positive and negative feelings of self-worth. The four-point scale ranges from strongly agree to strongly disagree. Overall scores range from 10 to 40, with higher scores indicating higher self-esteem. Internal consistency and Test-retest reliability for the RSE scale ranges from 0.77 to 0.88 . And 0.82 to 0.85 . Respectively.

\section{Procedure}

Permission to carry out the study was obtained from the departmental research committee of ICP and the Board of Advance Research and Studies (BASR). Permission for research investigation and data collection from the selected sample was obtained from school authorities via written and signed consent. Upon being granted permission, the sample was selected via purposive sampling. Participants who agreed to be part of the study were briefed about the purpose of the study and were ensured that their data would remain confidential. Data were obtained via objective self-report measures (i.e. RSE and ASQC).

\section{Statistical Analysis}

To understand the outcomes in numerical terms the SPSS software package was used. To investigate the association among all the study variables the Pearson Product Moment was calculated on the data. Furthermore, to explore the demographic features of the research sample descriptive statistics, like frequencies and percentages were also being calculated.

\section{Results}

Descriptive statistics (frequencies, mean, and percentages) of the participant's features and the correlation of the study variables are mention in this section. Findings indicate a noteworthy correlation between secure attachment styles and self-esteem $(\mathrm{r}=.118, \mathrm{P}=.116)$.

\section{Characteristics of Demographic Information:}

Table $1 \quad$ Mean and Standard Deviation of Age and Siblings

\begin{tabular}{cll}
\hline Variables & M & SD \\
\hline Age & 13.27 & 1.132 \\
Siblings & 4.83 & 3.318 \\
\hline
\end{tabular}

Table 1 reveals the mean and standard deviation of the participants, the mean age was found to be 13.27 whereas the mean of the number of siblings was 4.83 .

\section{Table 2}

Frequencies and percentages of demographic information of study participants,

\begin{tabular}{cll}
\hline & F & $\%$ \\
\hline Grade level & & \\
$6^{\text {th }}$ & 17 & 9.44 \\
$7^{\text {th }}$ & 37 & 20.56 \\
$8^{\text {th }}$ & 64 & 35.56 \\
$9^{\text {th }}$ & 62 & 34.44 \\
Family System & & \\
Joint & 50 & 27.78 \\
Nuclear & 130 & 72.22 \\
\hline
\end{tabular}




\begin{tabular}{ccc}
\hline Members Earning & & \\
1 & 124 & 68.89 \\
2 & 37 & 20.56 \\
3 & 13 & 7.22 \\
4 & 3 & 1.67 \\
5 & 2 & 1.11 \\
6 & 1 & 0.56 \\
\hline Members in Family & M & \\
\hline
\end{tabular}

Table 3

Descriptive Statistics for attachment styles and self-esteem.

\begin{tabular}{cll}
\hline \multicolumn{1}{c}{ Variables } & Mean & S.D \\
\hline Styles & 18.5111 & \\
Secure attachment & 14.3222 & 2.84121 \\
Anxious attachment & 15.35556 & 3.93474 \\
Avoidant attachment & 19.5722 & 2.932427 \\
Self-esteem & 3.43500 \\
\hline
\end{tabular}

Table 3 depicts the descriptive statistics of the study variables. The mean for attachment styles was 18.51 for secure attachment, 14.322 for Anxious, and 15.355 for Avoidant attachment styles.

Table 4

Correlation between attachment styles and self-esteem:

\begin{tabular}{lllllll}
\hline & \multicolumn{2}{l}{ Secure attachment } & \multicolumn{2}{l}{ Anxious attachment } & \multicolumn{2}{l}{ Avoidant attachment } \\
\hline \multirow{3}{*}{ Self esteem } & $\mathrm{r}$ & P-value & $\mathrm{R}$ & $\mathrm{P}$-value & $\mathrm{R}$ & P-value \\
\hline & 0.118 & 0.116 & 0.016 & 0.826 & -0.49 & 0.517 \\
\hline
\end{tabular}

$*<0.05$

Table 4 depicts the correlation analysis between the study variables. The results indicate that the secure attachment style is found to be positively correlated with self-esteem. Furthermore, the anxious style was found to have a weak relationship with self-esteem, furthermore, a negative relationship was found between the study variables of avoidant attachment style and self-esteem.

\section{Discussion}

The first assumption of the existing study was that "there would be a positive correlation between secure attachment style and self-esteem among adolescents." Analysis of results (see table 4) reveals that the secure attachment style is significantly positively correlated with self-esteem. The results of the current study are consistent with many previous studies. Research on self-esteem and attachment styles have shown that individuals with secure as well as dismissing attachment styles score higher on self-esteem measures than those with preoccupied attachment styles (Man \& Hamid, 1998)

A detailed review of the literature in this area indicates that a secure style of attachment developed in early childhood can significantly lower the risk of developing psychopathology in later adulthood. Research studying family dynamics emphasizes the family serving as the primary protective factor against psychopathology when fulfilling the role of serving as a safe base and thus aiding in the adolescent's overall wellbeing. Research further establishes the notion that adolescents who report having healthier relationships with their parents have higher levels of overall happiness due to feeling a strong sense of support, especially in times of distress, when they know they have a family they can turn to for help. Generally, these are the individuals who grow up experiencing a supportive environment, particularly one in which parents display consistent responsiveness to their needs in the critical years of their early childhood. As adults, these securely attached individuals are more open about themselves, find it easier to reach out for help, and allow people to lean on them emotionally in times of need. Their overall outlook on life is more positive, and in relationships, they can share greater intimacy and closeness (both physical and emotional), without fear of being rejected, abandoned, or overwhelmed, and have a more interdependent relationship with their partners.

The second hypothesis of the present study was that "There would be a negative correlation between insecure attachment style (anxious and avoidant) and self-esteem among adolescents" or that 
"Insecure attachment style (a) anxious and (b) avoidant, would be negatively correlated with selfesteem."

An analysis of results (see table 4) reveals that anxious attachment style was found to have a weak correlation with self-esteem; furthermore, a negative correlation was found between the study variable of avoidant attachment style and self-esteem. These findings are steady with earlier studies, which indicate that individuals with preoccupied, dismissing, and fearful attachment were lower in self-esteem than their secure counterparts (Man \& Hamid, 1998)

It has been established over the years, as the researcher has debated before in the section of introduction and literature, that youngsters who are arisen in distressed and troubled families with deprived family interactions, especially poor parental associations, are more disposed to development of psychopathology in future lifespan than those teenagers who belong to a well-adjusted family.

There is consistent evidence indicating that children from abusive households are victims of suffering from complex trauma. Without having a sense of safety and security found in securely attached relationships, these children tend to suffer from low self-worth and poor emotional regulation, even as adults. In clinical practice, it is often seen that when these adolescents enter into therapy, they are more likely to be diagnosed with personality disorders belonging to cluster B.

They become adults who desire a lot of connection within their relationships, sometimes to the point of being "clingy." They are highly aware of any slight changes in the relationship, which often results in poor quality and often short-term relationships (intimate or otherwise).

\section{Conclusion}

The analysis of results demonstrated that having a sense of being securely attached, i.e. feeling supported and like we can turn to our parents in times of need, plays a major role in the development of the self, particularly in terms of esteem.

As we have understood, self-esteem is the attitude or view that someone holds about themselves. This closely ties in with self-concept, which refers to the ability to reflect on one's traits, skills, and behavior. Self-esteem determines ultimately determines the number of facets in an individual's life, both as a child and an adult: how willing they may be to trying new challenges, how well they persist in difficulty, how to react to mistakes, setbacks, failures, and disappointment, how safe and competent they feel in the world, and how willing they may be to take risks and survive losses.

Children with healthy self-esteem can stand up for themselves and their values, take on new challenges, find accountability in their actions, experience a sense of importance, can accept that they are imperfect and accept their mistakes, and can experience and express greater happiness.

Cognitive neuroscience shows that the neural pathways developed in early childhood, particularly those from childhood traumatic experiences, play a significant role in shaping our responses in interpersonal dynamics, and these patterns of response are repeated throughout life.

It comes as no surprise that parents hold the primary responsibility for shaping the personality of their children, as well as other caregivers involved in the life of the growing child - this further includes adult relatives and teachers

\section{Implications}

Given the substantial impact of the relationship between child and caregiver, it appears significant that suitable strategies should be applied to understand how the development of serious consequences in terms of psychopathology can be prevented in the growing child.

Significant adults in the child's life (i.e. teachers and parents) need to ensure that they can foster a conducive environment for children to make them feel supported, heard, and accepted. Adults and caregivers should attempt to bring to the surface the child's own internal psychological resources (i.e. resilience) so that even when a sense of secure base may be absent, they can turn inwards and overcome adversity on their own.

The following implications, although prescribed primarily for parents, can be adopted by teachers and caregivers in the child's life as a means of creating a holistic framework for the child to grow up in. These implications are particularly important in Pakistan, as the nation strives to overcome toxic parenting techniques which are primarily based on punishment with parents who exercise authority and control. 
Upon birth, children lack an image of themself, which develops based on their interactions with primary caregivers. Through these interactions, children learn how valuable they are, depending on how caregivers respond to their needs and requests and what they tell the child they think of them.

I. Using a psychological mirror effectively - children develop a sense of being worthwhile or annoying, and capable and inept, as they pick up on words, tones, and actions in response to their needs and requests. It is important here for caregivers to convey to the child that they are excited to them see them grow, mature, develop, and explore

II. Becoming the child's secure base - caregivers should aim to develop a relationship in which the child can depend on the caregiver in which the child feels safe and accepted.

III. Using "being" messages - caregivers should communicate unconditional positive regard and love to their child, which adds directly to their self-esteem. This includes conveying messages like "you are everything I ever wanted", "you are important to me", "I'm glad you're here", "when you feel sad you can always talk to me", etc. Being messages can also be conveyed to children via behaviors such as hugging, smiling when they enter the room, and giving them time and positive attention. This helps a child to feel that they are a joy in the caregiver's life rather than a burden.

IV. Using "doing" messages - an important part of self-esteem relates to a person's sense of capability. Caregivers should make sure to focus on the child's talents and growth potential. "Doing" messages can include conveying messages such as "thank you for your help, it made things much easier", "that was very thoughtful of you", "I believe you will accomplish it very soon, I can see how hard you're working on it", etc.

V. Offering effective praise - caregivers should focus on the child's positive achievements and verbalize their appreciation, just as easily as they tend to do when criticizing a child. Children seek out their parent's praise and attempt to defer criticism. Not praising a child's positive behavior ultimately results in the child seeking out negative attention. Effective praise is immediate, specific, and sincere.

Apart from these critical implications, several other behaviors can be undertaken by caregivers including emphasizing the positive things that children do, having reasonable expectations, assigning meaningful tasks in which the child can experience success, setting limits and boundaries, giving undivided attention to the child during play, and using humor.

\section{Limitations and Recommendations}

The emphasis of this work was to target the variable of self-esteem and find its relationship with attachment styles. Not only is there scarcity in the field of research in Pakistan about attachment styles and self-esteem, but they also seem to be a lack of understanding of this concept in Pakistani culture (refer to implications)

The study is limited in terms of generalizability as only the private sector of education was targeted as the study sample. It is safe to assume that due to differences in literacy in education, children attending government schooling systems, as they tend to come from lower socio-economic backgrounds, experience a much different reality in childhood than those children who belong to the upper socio-economic strata. Research can be furthered to draw a comparison between attachment styles between socio-economic strata to further understand the difference in parenting styles and how this can affect attachment in early relationships.

Furthermore, gender differences can be taken into account for analyses when calculating the results as based on the observation that males may have increased self-esteem but to determine its link to secure attachment, further analysis is necessary.

For future studies, it is suggested that a larger sample size be recruited, and also include participants beyond Karachi. The participant pool should also be expanded to include adolescents from government sector schools as well as those with no educational background, as the literacy rate in Pakistan is about $50 \%$.

References

Ainsworth, M. D., \& Bell, S. M. (1970). Attachment, exploration, and separation: Illustrated by the behavior of one-year-olds in a strange situation. Child Development, 41(1), 49-67.

Ainsworth, M. D. S., Blehar, M., Waters, E., \& Wall, S. (1978). Patterns of attachment. Hillsdale, NJ: Erlbaum. 
Ainsworth, M. S. (1979). Infant-mother attachment. American Psychologist, 34(10), 932-937.

Bartholomew, K., \& Horowitz, L. M. (1991). Attachment styles among young adults: A test of a fourcategory model. Journal of Personality and Social Psychology, 61(2), 226-244.

Bartholomew, K. (1990). Avoidance of intimacy: An attachment perspective. Journal of Social and Personal Relationships, 7(2), 147-178.

Blatt, S. J. (1974). Levels of object representation in anaclitic and introjective depression. The Psychoanalytic Study of the Child 24: 107-157.

Bowlby, J. (1969). Attachment and loss: Attachment (Vol. 1). London: Hogarth Press.

Bowlby, J. (1982). Attachment and loss: Retrospect and prospect. American Journal of Orthopsychiatry, 52(4), 664-678.

Bowlby, J. (1988). A secure base: Parent-child attachment and healthy human development. New York: Basic Books.

Brennan, K. A., \& Bosson, J. K. (1998). Attachment-style differences in attitudes toward and reactions to feedback from romantic partners: An exploration of the relational bases of self-esteem. Personality and Social Psychology Bulletin, 24(7), 699-714.

Bretherton, I., \& Munholland, K. A. (1999). Internal working models in attachment relationships: A construct revisited. In J. Cassidy \& P. R. Shaver (Eds.), Handbook of attachment: Theory, research, and clinical applications (p. 89-111). The Guilford Press.

Bylsma, W. H., Cozzarelli, C., \& Sumer, N. (1997). The relation between adult attachment styles and global self-esteem. Basic and Applied Social Psychology, 19(1), 1-16.

Collins, N. L., \& Read, S. J. (1990). Adult attachment, working models, and relationship quality in dating couples. Journal of Personality and Social Psychology, 58(4), 644-663.

Consedine, N. S., Strongman, K. T., \& Magai, C. (2003). Emotions and behavior: Data from a crosscultural recognition study. Cognition and Emotion, 17(6), 881-902.

Cooper, M. L., Shaver, P. R., \& Collins, N. L. (1998). Attachment styles, emotion regulation, and adjustment in adolescence. Journal of Personality and Social Psychology, 74(5), 1380-1397.

Demir, Ayhan \& Tarhan, Nuray. (2001). Loneliness and Social Dissatisfaction in Turkish Adolescents. The Journal of psychology. 135. 113-23. 10.1080/00223980109603684.

DuBois, D. L., \& Hirsch, B. J. (2000). Self-Esteem in Early Adolescence: From Stock Character to Marquee Attraction. The Journal of Early Adolescence, 20(1), 5-11.

Erikson, E. H. (1950). Childhood and society. New York: Norton.

Feeney, J. A., \& Noller, P. (1990). Attachment style as a predictor of adult romantic relationships. Journal of Personality and Social Psychology, 58(2), 281-291.

Finzi, R., Har-Even, D., Weizman, A., Tyano, S., \& Shnit, D. (1996). The adaptation of the attachment style questionnaire for latency-aged children (Hebrew). Psychology, 5, 167-177.

Fraley, R. C. (2002). Attachment stability from infancy to adulthood: Meta-analysis and dynamic modeling of developmental mechanisms. Personality and Social Psychology Review, 6(2), 123-151.

Freeman, H., \& Brown, B. B. (2001). Primary attachment to parents and peers during adolescence: Differences by attachment style. Journal of Youth and Adolescence, 30(6), 653-674.

Griffin, D. W., \& Bartholomew, K. (1994). Models of the self and other: Fundamental dimensions underlying measures of adult attachment. Journal of Personality and Social Psychology, 67(3), 430-445.

Hazan, C., \& Shaver, P. (1987). Romantic love conceptualized as an attachment process. Journal of personality and social psychology, 52 (3), 511-524.

Hazan, C., \& Shaver, P. R. (1990). Love and work: An attachment theoretical perspective. Journal of Personality and Social Psychology, 59(2), 270-280.

Hinnen, C., Sanderman, R., \& Sprangers, M. A. G. (2009). Adult attachment as a mediator between the recollections of childhood and satisfaction with life. Clinical Psychology \& Psychotherapy, 16(1), 10-21 
Lee, A., \& Hankin, B. L. (2009). Insecure attachment, dysfunctional attitudes, and low self-esteem predicting prospective symptoms of depression and anxiety during adolescence. Journal of Clinical Child and Adolescent Psychology, 38(2), 219-231.

Levy, Sheri \& Stroessner, Steven \& Dweck, Carol. (1998). Stereotype Formation and Endorsement: The Role of Implicit Theories. Journal of Personality and Social Psychology. 74. 1421-1436. 10.1037/0022-3514.74.6.1421.

Lyons-Ruth, K., Bureau, J-F., Holmes, B., Easterbrooks, M., \& Brooks, N.H. (2013). Borderline symptoms and suicidality/self-injury in late adolescence: Prospectively observed relationship correlates in infancy and childhood. Psychiatry Research. 206. 273-281.

Marsh, H. W., \& O'Mara, A. (2008). Reciprocal effects between academic self-concept, self-esteem, achievement, and attainment over seven adolescent years: Unidimensional and multidimensional perspectives of self-concept. Personality and Social Psychology Bulletin, 34(4), 542-552.

McCarthy, G. \& Taylor, A. (1999), Avoidant/Ambivalent Attachment Style as a Mediator between Abusive Childhood Experiences and Adult Relationship Difficulties. Journal of Child Psychology and Psychiatry, 40: 465-477. doi:10.1111/1469-7610.00463.

Mikulincer, M. (1995). Attachment style and the mental representation of the self. Journal of Personality and Social Psychology, 69(6), 1203-1215.

Mikulincer, M. (1998). Attachment working models and the sense of trust: An exploration of interaction goals and affect regulation. Journal of Personality and Social Psychology, 74(5), $1209-1224$.

O'Connor, D. B., \& Conner, M. (2011). Effects of stress on eating behavior. In R. J. Contrada \& A. Baum (Eds.), the handbook of stress science: Biology, psychology, and health (p. 275-286). Springer Publishing Company.

Pace, U., \& Zappulla, C. (2011). Problem behaviors in adolescence: The opposite role played by insecure attachment and commitment strength. Journal of Child and Family Studies, 20, 854862.

Pace, U., \& Zappulla, C. (2013). Detachment from Parents, Problem Behaviors, and the Moderating Role of Parental Support among Italian Adolescents. Journal of Family Issues, 34(6), 768783.

Pearce, J. W., \& Pezzot-Pearce, T. D. (2007). Psychotherapy of abused and neglected children (2nd $E d$.). Guilford Press.

Sarason, B. R., Pierce, G. R., \& Sarason, I. G. (1990). Social support: The sense of acceptance and the role of relationships. In B. R. Sarason, I. G. Sarason, \& G. R. Pierce (Eds.), Wiley series on personality processes. Social support: An interactional view (p. 97-128). John Wiley \& Sons.

Rosenberg, M. (1965). Society and the Adolescent Self-Image. Princeton, NJ: Princeton University Press.

Salzman, J., 1996. Primary Attachment in Female Adolescents: Association with Depression, SelfEsteem, and Maternal Identification. Psychiatry, 59(1), pp.20-33.

Santrock, J. W. (1997). Life-span development (6th Ed.). Brown \& Benchmark Publishers.

Schimmenti, A. \& Bifulco, A. (2013). Linking lack of care in childhood to anxiety disorders in emerging adulthood: The role of attachment styles. Child and Adolescent Mental Health. 20. 10.1111/camh.12051.

Schimmenti, A. (2016). the Developmental Roots of Dissociation: A Multiple Mediation Analysis. Psychoanalytic Psychology. 34. 96-105. 10.1037/pap0000084.

Schimmenti, A., Di Carlo, G., Passaic, A., \& Caretti, V. (2014). Abuse in Childhood and Psychopathic Traits in a Sample of Violent Offenders. Psychological Trauma: Theory, Research, Practice, and Policy. DOI: 10.1037/tra0000023. 10.1037/tra0000023.

Schimmenti, A. (2012). Unveiling the hidden self: Developmental trauma and pathological shame. Psychodynamic Practice: Individuals, Groups and Organizations, 18(2), 195-211

Schore, A. N. (1998). Early shame experiences and infant brain development. In P. Gilbert \& B. Andrews (Eds.), Series in affective science. Shame: Interpersonal behavior, psychopathology, and culture (p. 57-77). Oxford University Press. 
Seiffge-Krenke, I. (2006). Coping with Relationship Stressors: The Impact of Different Working Models of Attachment and Links to Adaptation. Journal of Youth and Adolescence, 35(1), 25-39.

Shaver, P., Hazan, C., \& Bradshaw, D. (1988). Love as an attachment. In R. J. Sternberg \& M. L. Barnes (Eds.), the psychology of love (p. 68-99). Yale University Press.

Sroufe, L. (2005). Attachment categories as reflections of multiple dimensions: Comment on Fraley and spieker. Developmental Psychology, 39 (3), 413-416.

Yagon, M., \& Mikulincer, M. (2004). Socioemotional and academic adjustment among children with learning disorders: The mediational role of attachment-based factors. The Journal of Special Education, 38(2), 111-123. 